\title{
AIDS and UK respiratory physicians: attitudes to confidentiality, infection control, and
}

\section{management}

\author{
S Church, S Owen, A A Woodcock
}

\begin{abstract}
Respiratory physicians are concerned in the management of most patients with AIDS. Attitudes and practices of 463 respiratory physicians in the United Kingdom in relation to confidentiality, infection control, and treatment were sought by questionnaire from December 1987 to March 1988; 266 replies were received. Thirty eight per cent of respondents had not seen an HIV positive patient at the time of the survey. Respiratory physicians followed General Medical Council guidelines in relation to consent and confidentiality, except that if the patient's consent was withheld three quarters of the physicians would still inform an at risk hospital health care worker; only a quarter, however, would inform an at risk spouse. Routine infection control was frequently inadequate and "disease specific"-that is, substantially increased for known HIV positive patients. Given an HIV positive patient with respiratory symptoms and an abnormal chest radiograph, two thirds of respiratory physicians said that they would treat empirically for Pneumocystis carinii pneumonia as opposed to immediate bronchoscopy for accurate diagnosis. If a patient with AIDS who had pneumocystis pneumonia developed respiratory failure, half the physicians said at that time that they would elect not to ventilate the patient.
\end{abstract}

The acquired immunodeficiency syndrome (AIDS) will be an increasingly common problem for respiratory physicians as most patients with AIDS develop pulmonary complications at some stage of their illness. ${ }^{1}$ Diagnostic procedures for these complications include fibreoptic bronchoscopy with bronchoalveolar lavage and transbronchial biopsy. ${ }^{2}$ Other health care workers besides doctors, including endoscopy nurses, physiotherapists, and intensive care personnel, play a part in treatment. Even in high prevalence areas, many primary care physicians have shown a lack of knowledge and skills relevant to AIDS $^{3}$ and there are many controversial areas in the care of patients with AIDS. We therefore conducted a survey of all respiratory physicans in the United Kingdom to determine their attitudes to confidentiality, infection control, and treatment of patients with AIDS.

\section{Methods}

All 398 consultants and 65 senior registrars in respiratory medicine in the UK were surveyed by postal questionnaire from December 1987 to March 1988. The questionnaire was confidential and a single reminder was sent. Where personal opinions were requested individual data are presented, but in matters of unit policy, such as infection control, we considered only one reply from each hospital, from the most senior respondent.

Patients were defined as follows: routine patients (that is, no known risk factors); high risk (for example homosexuals, intravenous drug abusers); known HIV positive and AIDS patients.

\section{Results}

We received 266 replies. The response rate was $56 \%(224 / 398)$ for consultants and $65 \%$ $(42 / 65)$ for senior registrars. Some responders did not complete the entire questionnaire satisfactorily, and the denominator for the percentages given below therefore varies. One hundred and one $(38 \%$ ) respondents had never seen an HIV positive patient or a patient with AIDS and only $11(4 \%)$ had seen more than 20 . The nominated district AIDS physicians by specialty were as follows: respiratory $78 / 253$ $(31 \%)$, infectious diseases $59(23 \%)$, genitourinary $20(8 \%)$, gastroenterology $16(6 \%)$, haematology $10(4 \%)$, miscellaneous or none $70(28 \%)$.

The sexual orientation of patients formed part of the routine clinical history for $11(4 \%)$ of the physicians; $160(60 \%)$ inquired only when suspicious.

Eighty four per cent of respiratory physicians thought that AIDS should be a notifiable disease.

Informed consent was "usually" (that is, whenever possible) obtained before HIV antibody testing by all respondents except one. When the HIV test gave a positive result 253 $(95 \%)$ of respondents, with the patient's consent, would inform both hospital based and primary health care workers and the spouse. If consent was withheld, however, $200(75 \%)$ would inform hospital based and $160(60 \%)$ primary health care workers; only $67(25 \%)$ would inform an at risk spouse.

INFECTION CONTROL

Respiratory physicians took much greater precautions to avoid body fluid contamination when undertaking bronchoscopy in a patient with AIDS than with a routine patient (table 1 ). 
Table 1 Comparison of infection control precautions and bronchoscope sterilisation times for routine patients versus patients with AIDS used by bronchoscopists, physiotherapists, and intensive care personnel

\begin{tabular}{|c|c|c|}
\hline & $\begin{array}{l}\text { Routine } \\
(\text { No }(\%))\end{array}$ & $\begin{array}{l}A I D S \\
(\text { No }(\%))\end{array}$ \\
\hline $\begin{array}{l}\text { Bronchoscopy precautions: } \\
\text { Gloves } \\
\text { Gown } \\
\text { Goggles or spectacles }\end{array}$ & $\begin{array}{rr}\mathrm{n}=201 \\
142 & (71) \\
79 & (39) \\
12 & (6)\end{array}$ & $\begin{array}{lc}\mathrm{n}= & 199 \\
195 & (98) \\
174 & (90) \\
167 & (87)\end{array}$ \\
\hline $\begin{array}{c}\text { Sterilisation times: } \\
0-30 \mathrm{~min} \\
31 \mathrm{~min}-12 \mathrm{~h} \\
>12 \mathrm{~h}\end{array}$ & $\begin{array}{rr}\mathrm{n}= & 123 \\
119 & (97) \\
4 & (3) \\
0 & (0)\end{array}$ & $\begin{array}{rr}\mathrm{n}=118 \\
35 & (30) \\
79 & (67) \\
4 & (3)\end{array}$ \\
\hline $\begin{array}{l}\text { Physiotherapists' precaution } \\
\text { Gloves } \\
\text { Gown } \\
\text { Goggles }\end{array}$ & $\begin{array}{cr}\mathrm{n}= & 212 \\
8 & (4) \\
6 & (3) \\
0 & (0)\end{array}$ & $\begin{array}{rr}\mathrm{n}=207 \\
100 & (48) \\
93 & (45) \\
44 & (21)\end{array}$ \\
\hline $\begin{array}{l}\text { Intensive care personnel } \\
\text { precautions: } \\
\text { Gloves } \\
\text { Gown } \\
\text { Goggles } \\
\text { Overshoes }\end{array}$ & $\begin{aligned} \mathrm{n}= & 205 \\
98 & (48) \\
50 & (24) \\
1 & (0 \cdot 5) \\
9 & (4)\end{aligned}$ & $\begin{array}{ll}\mathrm{n}= & 204 \\
142 & (70) \\
128 & (63) \\
78 & (38) \\
41 & (20)\end{array}$ \\
\hline
\end{tabular}

For routine patients over a quarter did not wear gloves and nearly two thirds did not wear a gown. Six per cent normally wore spectacles, but none wore goggles specifically for bronchoscopy.

There appeared to be major deficiencies in equipment in many bronchoscopy units (table 2). Two per cent glutaraldehyde was used universally for sterilisation of the bronchoscope. Twenty per cent of bronchoscopists were unaware of sterilisation times; the times reported varied enormously but were considerably increased after a bronchoscope had been used in a patient with AIDS (table 1).

Fifteen of $206(7 \%)$ of physicians had a separate spirometer for high risk patients. One hundred and fifty seven of $186(84 \%)$ refused to allow high risk patients to undergo measurements of carbon monoxide gas transfer because rebreathing from the equipment is necessary.

One third of the physicians $(61 / 212)$ did not know what precautions were taken by physiotherapists in their unit. The others reported a considerable increase in routine infection control precautions for patients with AIDS by both physiotherapists and intensive care personnel.

After taking a routine blood specimen, half $(117 / 256)$ of the physicians resheathed the needle before placing it in a disposal box. Fifty three of $252(21 \%)$ took no precautions if they had an open cut or abrasion on their hands before taking blood.

PATIENT MANAGEMENT

If an HIV positive patient developed respiratory symptoms with an abnormal chest radiograph, 166 of $258(64 \%)$ physicians would treat empirically for pneumocystis pneumonia with co-trimoxazole, adding bronchoscopy only if there was no response to treatment. Eighty $\left(31_{0}^{\circ}\right)$ would perform bronchoscopy immediately and treat only for pathogens that were isolated. Twelve $\left(5^{\circ}\right)$ would treat without bronchoscopy under any circumstances. If a patient with AIDS who had pneumocystis pneumonia developed respiratory failure, 130 of $244\left(53^{\circ}{ }_{0}\right)$ said that they would elect not to ventilate the patient.

The physicians' views about the placement of patients with AIDS were as follows: Acutely ill: open ward $34 / 247(14 \%)$, single cubicle $137\left(56^{\circ}{ }_{0}\right)$, designated AIDS unit $72(30 \%)$. Terminal care: home $111 / 256(43 \%)$, hospice $64\left(25^{\circ}{ }_{0}\right)$, home and hospice $33(13 \%)$, home and hospital $48(19 \%)$.

\section{Discussion}

Most patients with AIDS develop pulmonary complications that may require invasive procedures to obtain a diagnosis and as a consequence respiratory physicians will be concerned with most of these patients. Yet by March 1988 only one third of the nominated district AIDS physicians were respiratory physicians.

We achieved a response rate of only $58 \%$ to the questionnaire, despite reminders. Those sufficiently motivated to reply had very variable practices in relation to HIV infection. The data were collected from December 1987 to March 1988 and since then changes in attitudes and policy will inevitably have occurred with increasing exposure to HIV infection and AIDS.

Most respiratory physicians thought that AIDS should be a notifiable disease. Almost all respiratory physicians followed the advice of the General Medical Council that doctors are expected in normal circumstances to ensure that patients consent to HIV testing. ${ }^{4}$ Respiratory physicians would inform fellow health care workers and the at risk spouse with the patient's consent. If, however, the patients's consent were withheld, most respiratory physicians said that they would breach patient confidentiality to inform at risk health care workers, though only a quarter of the physicians would inform a spouse, who is potentially at much greater risk.

The AIDS issue has been instrumental in forcing a review of infection control policy. Emphasis has switched from "disease specific" (that is, identify the infectious patient and apply measures to that individual) to "universal" infection control (that is, universally high standards of hygiene adequate to cover all pathogens in every patient for each procedure $^{56}$ ).

At the time of the survey most respiratory physicians, physiotherapists, and personnel of intensive care units still operated a "disease specific" policy. For example, infection control

Table 2 Bronchoscopy equipment in 191 respiratory units in the UK (December 1987-March 1988)

\begin{tabular}{lllllll}
\hline & $\begin{array}{l}\text { One or more immersible } \\
\text { bronchoscopes }\end{array}$ & Automatic washer & Ultrasonic forceps cleaner & $\begin{array}{c}\text { "Dedicated" bronchoscope } \\
\text { for HIV patients }\end{array}$ \\
\hline No $(\%)$ & $160(84)$ & $34(19)$ & $74(39)$ & $39(20)$ \\
\hline
\end{tabular}


was largely inadequate for routine patients undergoing bronchoscopy but was substantially increased for the identified infectious patient. The greatest danger to health care workers are the symptomless infectious individuals, who without serological testing are impossible to identify. ${ }^{7}$ As many respiratory physicians inquired about sexual orientation only when suspicious, they presumably believed that they could recognise high risk individuals. The American College of Physicians recommends routine inquiry about sexual orientation with all patients. ${ }^{8}$

Attempts by bronchoscopists to formulate an infection control policy were initially frustrated by lack of information on the susceptibility of microorganisms to cleaning and disinfection in a clinical environment. ${ }^{9}$ This may explain the enormous variability in bronchoscope sterilisation times for routine patients. The latest infection control policy recommendations ${ }^{10}$ are based on work published after this survey. ${ }^{11}$ Recommendations include adopting a universal infection control policy, soaking the well cleaned bronchoscope in $2 \%$ alkaline glutaraldehyde for at least 20 minutes between cases, and the phasing out of non-immersible bronchoscopes. It is disturbing that at the time of this survey one in six respiratory units in the United Kingdom still did not possess a fully immersible bronchoscope and one in five units reserved a "dedicated" bronchoscope for HIV or high risk patients. These are frequently the older, non-immersible bronchoscopes, which are impossible to clean completely and may be responsible for cross infection between immunosuppressed patients. ${ }^{9}$

The management of the HIV positive patient with respiratory symptoms and an abnormal chest radiograph is controversial, the options being invasive investigation with treatment appropriate for the aetiological agent ${ }^{12}$ or empirical treatment for pneumocystis pneumonia. ${ }^{1314}$ Two thirds of the respiratory physicians in the United Kingdom in our survey favoured empirical treatment. This probably represents a pragmatic approach, but there may have been an element of unwillingness on the part of physicians to perform bronchoscopy on a potentially infectious patient.

Early experience with patients with AIDS and severe pneumocystis pneumonia who developed respiratory failure requiring ventilation suggested an $80-90 \%$ mortality, ${ }^{15}$ though recent reports indicate improved survival. ${ }^{16}$ In our survey more than half of the UK respiratory physicians replying said that they would not ventilate such a patient by choice. Patients' attitudes to ventilation change as the disease progresses ${ }^{17}$ and may be influenced by a negative attitude on the part of physicians. ${ }^{15}$ With improved anti-pneumocystis treatment, the advent of effective anti-HIV treatment, the introduction of continuous positive airway pressure and use of methyl prednisolone, the attitudes to ventilation of patients with AIDS who develop respiratory failure are at present under revision. ${ }^{18}$

Respiratory physicians are going to bear the brunt of the AIDS epidemic and patients will continue to present in increasing numbers. This survey investigated the early attitudes of respiratory physicians to patients infected with HIV and the findings highlight important deficiencies in infection control for invasive procedures at the time of the study. Scientific data, particularly on the susceptibility of respiratory pathogens to cleaning and disinfection, are now available ${ }^{11}$ and a sensible "universal" infection control policy can now be formulated; it remains to be seen whether this will be widely adopted.

We are grateful to Linda Hunt for computation and Jane Feltham for typing the manuscript.

1 Millar AB. Respiratory manifestations of AIDS. $\mathrm{Br} J$ Hosp Med 1988;39:204-15

2 Murray JF, Felton CP, Garay SM, et al. Pulmonary complications of the acquired immune deficiency syndrome: a report of the National Heart, Lung and Blood Workshop. $N$ Engl J Med 1984;310:1682-8.

3 Lewis CE, Freeman HE, Corey CR. AIDS related competence of California's Primary Care Physicians. Am J Publ Health 1987;77:795-9.

4 Walton J, Irvine D. London: General Medical Council, 1988.

5 Lynch P, Jackson MM. Isolation practices: how much is too much, or not enough? Asepsis 1986;8:2-5.

6 Garner JS, Hughes JM. Options for isolation precautions. Ann Intern Med 1987;107:248-50.

7 Kelen GD, Fritz S, Qaqish B, et al. Unrecognised human immunodeficiency virus infection in emergency department patients. N Engl J Med 1988;318:1645-50.

8 Health and Public Policy Committee, American College of Physicians, and the Infectious Diseases Society of America. Acquired immunodeficiency syndrome. Ann Intern Med 1986;104:575-81.

9 Hansen PJV, Jeffries DJ, Batten JC, Collins JV. Infection control revisited: dilemma facing today's bronchoscopists. Br Med J 1988;297:185-7.

10 Bronchoscopy and Infection Control. British Thoracic Society. Lancet 1989;ii:270-1.

11 Hanson PJV, Gove D, Jeffries DJ, Collins JV. Chemical inactivation of HIV on surfaces. Br Med $J$ 1989;298: 862-4.

12 Broaddus C, Dake MD, Stulbarg MS, et al. Bronchoalveolar lavage and transbronchial biopsy for the diagnosis of pulmonary infections in the acquired immunodeficiency syndrome. Ann Intern Med 1985;102:747-52.

13 Pozniak AL, Tung K, Swinburn CR, et al. Clinical and bronchoscopic diagnosis of suspected pneumonia related bronchoscopic diagnosis of suspected

14 Miller RF, Millar AB, Weller IUD, Semple SJG. Empirical treatment without bronchoscopy for Pneumocystis carinii pneumonia in the acquired immunodeficiency syndrome. Thorax 1989;44:559-64.

15 Wachter RM, Luce JM, Turner J, Volberding P, Hopewell PC. Intensive care of patients with the acquired immunodeficiency syndrome: outcome and changing immunodeficiency syndrome: outcome and changing

16 El-Sadt W, Sumkerkott MS. Survival and prognostic factors in severe pneumocystis carinii pneumonia requiring in severe pneumocystis carinii pneumonia requiring
mechanical ventilation. Am Rev Respir Dis 1988;137: mechanice 7 .

17 Steinbrook R, Lo B, Moulton J, et al. Preferences of homosexual men with AIDS for life-sustaining treatment. N Engl J Med 1986;314:457-60.

18 Luce JM, Wachter RM, Hopewell PC. Intensive care of patients with the acquired immunodeficiency syndrome: time for a reassessment? Am Rev Respir Dis 1988;137: 1261-3. 